\title{
Corrigendum: Living on the Edge of the CNS: Meninges Cell Diversity in Health and Disease
}

\author{
Julia Derk ${ }^{1 *}$, Hannah E. Jones ${ }^{1,2}$, Christina Como ${ }^{1,3}$, Bradley Pawlikowski ${ }^{1}$ and \\ Julie A. Siegenthaler ${ }^{1,2,3 *}$ \\ ${ }^{1}$ Section of Developmental Biology, Department of Pediatrics, University of Colorado, Aurora, CO, United States, ${ }^{2}$ Cell \\ Biology, Stem Cells and Development Graduate Program, University of Colorado, Anschutz Medical Campus, Aurora, CO, \\ United States, ${ }^{3}$ Neuroscience Graduate Program, University of Colorado, Aurora, CO, United States
}

Keywords: meninges, fibroblast, meningeal lymphatic system, arachnoid barrier, blood-CSF barrier, borderassociated macrophages

\section{A Corrigendum on}

Living on the Edge of the CNS: Meninges Cell Diversity in Health and Disease by Derk, J., Jones, H. E., Como, C., Pawlikowski, B., and Siegenthaler, J. A. (2021). Front. Cell. Neurosci. 15:703944. doi: 10.3389/fncel.2021.703944

\section{OPEN ACCESS}

Edited and reviewed by: Peggy Assinck,

University of Edinburgh, United Kingdom

${ }^{*}$ Correspondence:

Julia Derk

julia.derk@cuanschutz.edu

Julie A. Siegenthaler

julie.siegenthaler@cuanschutz.edu

Specialty section:

This article was submitted to

Non-Neuronal Cells,

a section of the journal

Frontiers in Cellular Neuroscience

Received: 19 August 2021 Accepted: 14 September 2021

Published: 08 October 2021

Citation:

Derk J, Jones HE, Como C, Pawlikowski B and Siegenthaler JA (2021) Corrigendum: Living on the

Edge of the CNS: Meninges Cell Diversity in Health and Disease. Front. Cell. Neurosci. 15:761506. doi: 10.3389/fncel.2021.761506
In the original article Yao et al., 2018 was not cited in the article. The citation has now been inserted in Meningeal cell types, Immune cells, Paragraph 3 and should read:

Macrophages of the meninges are one of better documented meningeal immune cell and belong to a highly specialized class of macrophages called border associated macrophages (BAMs). BAMs and microglia both originate from yolk sac erythro-myeloid progenitors and can be detected in the brain as early as E10 (Utz et al., 2020). As development continues BAMs and microglia segregate both physically and transcriptionally, with BAMs remaining in the leptomeninges (they are also in the choroid plexus and perivascular spaces) and expressing CD206 and Lyve1 which are not expressed by microglia. In the adult, leptomeningeal BAMs are defined by expression of CD206, Lyve1, P2rx7, and Egfl7 and have significantly different transcriptional profiles from dural BAMs (Mrdjen et al., 2018; Van Hove et al., 2019). Adult dural BAMs don't express Lyve1 and can also be divided in subgroups. For example, one group of dural BAMs has low expression of major histocompatibility complex II (MHCII ${ }^{l o}$ ) and express Clec4n, Clec10a, Folr2, while MHCII ${ }^{\text {hi }}$ dural BAMs express greater CCR2, implicating a monocytic origin. Another important difference is that leptomeningeal BAMS are long lived while dural BAMs are continuously renewed by peripheral monocytes (Goldmann et al., 2016; Van Hove et al., 2019). The bone marrow in the calvarium and vertebral column specifically supply monocytes and neutrophils to the dura during homeostasis (Cugurra et al., 2021) and to the meninges and brain parenchyma following brain injury or in neuroinflammation via vascular tunnels connecting the bone marrow and dura (Herisson et al., 2018; Yao et al., 2018; Cai et al., 2019; Cugurra et al., 2021). The unique properties seen among leptomeningeal and dural BAMs is consistent with specialized functions for these populations in their respective barrier and non-barrier compartments.

In the original article, there was an error. We omitted reference to an important access mechanism for cancer cells to enter the CNS, vascular channels from the calvarial bone to the meninges described in Yao et al., 2018 Nature.

A correction has been made to Meningeal response to injury and disease, Meninges as a site of cancer metastasis, Paragraph 1:

Primary tumors of the meninges are quite rare, however, the leptomeninges is a relatively 
common site for by contiguous extension of primary tumors of the central nervous system, paranasal sinuses and skull base origin or tumor metastasis which can lead to dissemination into the CNS parenchyma and poor prognosis (Mahendru and Chong, 2009; Waki et al., 2009; Oechsle et al., 2010; Scott and Kesari, 2013). Cancer cells may enter the meninges via the choroid plexus, the brain, by crossing pial blood vessels or by vascular channels that connect the bone marrow and meninges (Redmer, 2018; Yao et al., 2018). To cross the BBB, tumor cells bind endothelial cells and disrupt their tight junctions (Bos et al., 2009; Kienast et al., 2010; Fazakas et al., 2011; Redmer, 2018). Melanoma cells adhere to and disturb the interaction of brain endothelial cells, which maintain the integrity of the BBB, through a disruption of tight and adherence junction proteins such as Claudin 5 and ZO-1. In addition, proteolytic enzymes

\section{REFERENCES}

Bos, P. D., Zhang, X. H.-F., Nadal, C., Shu, W., Gomis, R. R., Nguyen, D. X., et al. (2009). Genes that mediate breast cancer metastasis to the brain. Nature 459, 1005-1009. doi: 10.1038/nature08021

Cai, R., Pan, C., Ghasemigharagoz, A., Todorov, M. I., Förstera, B., Zhao, S., et al. (2019). Panoptic imaging of transparent mice reveals whole-body neuronal projections and skull-meninges connections. Nat. Neurosci. 22, 317-327. doi: 10.1038/s41593-018-0301-3

Cugurra, A., Mamuladze, T., Rustenhoven, J., Dykstra, T., Beroshvili, G., Greenberg, Z. J., et al. (2021). Skull and vertebral bone marrow are myeloid cell reservoirs for the meninges and CNS parenchyma. Science eabf7844. doi: 10.1126/science.abf7844

Fazakas, C., Wilhelm, I., Nagyoszi, P., Farkas, A. E., Haskó, J., Molnár, J., et al. (2011). Transmigration of melanoma cells through the blood-brain barrier: role of endothelial tight junctions and melanoma-released serine proteases. PLoS One 6:e20758. doi: 10.1371/journal.pone.0020758

Goldmann, T., Wieghofer, P., Jordão, M. J. C., Prutek, F., Hagemeyer, N., Frenzel, K., et al. (2016). Origin, fate and dynamics of macrophages at central nervous system interfaces. Nat. Immunol. 17, 797-805. doi: 10.1038/ni.3423

Herisson, F., Frodermann, V., Courties, G., Rohde, D., Sun, Y., Vandoorne, K., et al. (2018). Direct vascular channels connect skull bone marrow and the brain surface enabling myeloid cell migration. Nat. Neurosci. 21, 1209-1217. doi: 10.1038/s41593-018-0213-2

Kienast, Y., von Baumgarten, L., Fuhrmann, M., Klinkert, W. E. F., Goldbrunner, R., Herms, J., et al. (2010). Real-time imaging reveals the single steps of brain metastasis formation. Nat. Med. 16, 116-122. doi: 10.1038/nm.2072

Mahendru, G., and Chong, V. (2009). Meninges in cancer imaging. Cancer Imaging 9 Spec No A, S14-S21. doi: 10.1102/1470-7330.2009.9004

Mrdjen, D., Pavlovic, A., Hartmann, F. J., Schreiner, B., Utz, S. G., Leung, B. P., et al. (2018). High-dimensional single-cell mapping of central nervous system immune cells reveals distinct myeloid subsets in health, aging, and disease. Immunity 48, 380-395.e6. doi: 10.1016/j.immuni.2018.01.011

Oechsle, K., Lange-Brock, V., Kruell, A., Bokemeyer, C., and de Wit, M. (2010). Prognostic factors and treatment options in patients with leptomeningeal such as heparanase and seprase are important for the capacity of metastatic cells to traverse the BBB and occupy the brain (Fazakas et al., 2011). Here, micrometastases give rise to macrometastases through proliferation along brain microvessels (Kienast et al., 2010). Additionally, breast cancer cells express ST6GALNAC5, which is normally exclusively expressed in the brain, allowing for increased adhesion to brain endothelial cells to pass through the BBB (Bos et al., 2009). Further, acute lymphoblastic leukemia cells access the CNS via vascular channels that exist between bone marrow located in the vertebral and calvarium bone and the meninges (Yao et al., 2018).

The authors apologize for this error and state that this does not change the scientific conclusions of the article in any way. The original article has been updated. metastases of different primary tumors: a retrospective analysis. J. Cancer Res. Clin. Oncol. 136, 1729-1735. doi: 10.1007/s00432-010-0831-x

Redmer, T. (2018). Deciphering mechanisms of brain metastasis in melanoma - the gist of the matter. Mol. Cancer 17:106. doi: 10.1186/s12943-018-0854-5

Scott, B. J., and Kesari, S. (2013). Leptomeningeal metastases in breast cancer. Am. J. Cancer Res. 3, 117-126.

Utz, S. G., See, P., Mildenberger, W., Thion, M. S., Silvin, A., Lutz, M., et al. (2020). Early fate defines microglia and non-parenchymal brain macrophage development. Cell 181, 557-573.e18. doi: 10.1016/j.cell.2020.03.021

Van Hove, H., Martens, L., Scheyltjens, I., De Vlaminck, K., Pombo Antunes, A. R., De Prijck, S., et al. (2019). A single-cell atlas of mouse brain macrophages reveals unique transcriptional identities shaped by ontogeny and tissue environment. Nat. Neurosci. 22, 1021-1035. doi: 10.1038/s41593-019-0393-4

Waki, F., Ando, M., Takashima, A., Yonemori, K., Nokihara, H., Miyake, M., et al. (2009). Prognostic factors and clinical outcomes in patients with leptomeningeal metastasis from solid tumors. J. Neurooncol. 93, 205-212. doi: 10.1007/s11060-008-9758-3

Yao, H., Price, T. T., Cantelli, G., Ngo, B., Warner, M. J., Olivere, L., et al. (2018). Leukaemia hijacks a neural mechanism to invade the central nervous system. Nature 560, 55-60. doi: 10.1038/s41586-018-0342-5

Publisher's Note: All claims expressed in this article are solely those of the authors and do not necessarily represent those of their affiliated organizations, or those of the publisher, the editors and the reviewers. Any product that may be evaluated in this article, or claim that may be made by its manufacturer, is not guaranteed or endorsed by the publisher.

Copyright (c) 2021 Derk, Jones, Como, Pawlikowski and Siegenthaler. This is an open-access article distributed under the terms of the Creative Commons Attribution License (CC BY). The use, distribution or reproduction in other forums is permitted, provided the original author(s) and the copyright owner(s) are credited and that the original publication in this journal is cited, in accordance with accepted academic practice. No use, distribution or reproduction is permitted which does not comply with these terms. 